\title{
Two-step LASIK after penetrating keratoplasty
}

This article was published in the following Dove Press journal:

Clinical Ophthalmology

19 October 2009

Number of times this article has been viewed

\author{
Aris N Kollias \\ Markus M Schaumberger \\ Thomas C Kreutzer \\ Michael W Ulbig \\ Carlo A Lackerbauer \\ University Eye Hospital, \\ Ludwig-Maximilians University, \\ Munich, Germany
}

Correspondence: Aris Kollias

University Eye Hospital, Ludwig-

Maximilians University, Mathildenstr. 8 , 80336 Munich, Germany

$\mathrm{Tel}+49895 \mathrm{I} 6038 \mathrm{lI}$

Fax +498951605160

Email akollias@med.uni-muenchen.de
Purpose: The point of interest of this retrospective case review is to study refractive changes caused by the hinged lamellar keratotomy and the refractive outcome after laser ablation in a second step within the scope of laser in situ keratomileusis (LASIK) in patients with penetrating keratoplasty.

Methods: Data from eight patients obtained before lamellar keratotomy, before laser ablation, and three months later were evaluated. Keratotomies were performed with the Moria ${ }^{\circledR}$ LSK one and the Amadeus ${ }^{\circledR} 2$ microkeratome, laser ablation was performed with the Schwind ${ }^{\circledR}$ Keratome I and the Wavelight ${ }^{\circledR}$ Allegretto WaveEyeQ.

Results: Uncorrected visual acuity (UCVA) improved significantly from 1 [logMar] to 0.4 [logMar] at the last visit. Median gain of UCVA was $7.38 \pm 2.96$ Snellen lines. Best spectacle-corrected visual acuity did not change significantly. Preoperative manifest refraction spherical equivalent decreased from $-4.02 \pm 4.77$ diopters (D) to $-1.11 \pm 2.45 \mathrm{D}$ after laser ablation. Mean preoperative manifest astigmatism was $-7.27 \pm 3.65 \mathrm{D}$, after lamellar keratotomy $-6.72 \pm 3.68 \mathrm{D}$, and after laser ablation $-2.08 \pm 1.80 \mathrm{D}$. Manifest astigmatism did not change significantly after the keratotomy.

Conclusions: Lamellar keratotomy causes biomechanical changes to the cornea. We favor a two-step LASIK in penetrating keratoplasty patients in order to improve precision and predictability of the refractive outcome.

Keywords: two-step, cornea, LASIK, keratoplasty, astigmatism

\section{Introduction}

Microsurgical techniques have improved the functional outcome of penetrating keratoplasty (PK), but high spherocylindrical refractive errors are quite common after PK. ${ }^{1}$ They often cannot be corrected by spectacles due to aniseikonia, therefore surgical approaches are of interest. Laser in situ keratomileusis (LASIK) is a widely accepted method for treating a great range of refractive errors and has been successfully used in treating patients requiring refractive surgery after PK as well. ${ }^{2-7}$ The purpose of this retrospective chart review was to examine the refractive changes induced by the hinged lamellar keratotomy alone and the refractive outcome after laser ablation in a second step in patients with corneal grafts.

\section{Patients and methods}

Data from eight consecutive patients who had two-step LASIK after PK in our department was evaluated. The study included five female and three male patients. The mean age was 54 years (range 8 to 90 years). Four patients suffered from Fuchs endothelial dystrophy, two patients from keratoconus, one from 
posttraumatic scares, and in one case the cause for PK was unknown. Three patients were pseudophacic, the other five participating patients had a clear crystalline lens. All participating patients had an average intraocular pressure of $14.7 \mathrm{~mm}$ of mercury (range 8 to $18 \mathrm{mmHg}$ ) and besides the corneal transplant no other abnormal ocular findings.

Data collected included uncorrected visual acuity (UCVA), best spectacle-corrected visual acuity (BSCVA), manifest refraction (Table 1), corneal refractive power, and corneal thickness, and were obtained before lamellar keratotomy, before laser ablation, and three months later. The average interval between date of PK and lamellar keratotomy was 6.1 years (range 1.8 to 10.5 years). The time between PK and suture removal was in all cases over six months and the average period between lamellar keratotomy and laser ablation was $51.9 \pm 31.6$ days (range 21 to 100 days). Keratotomies were performed in one case with the Moria ${ }^{\circledR}$ LSK One microkeratome (Moria, Antony, France), in the other seven cases with the Amadeus ${ }^{\circledR}$ II microkeratome (Ziemer Ophthalmic Systems, Port, Switzerland) and the hinges were placed nasally. The size of the corneal flap ranged from 8.5 to $9.0 \mathrm{~mm}$ and cut depth from 140 to $160 \mu \mathrm{m}$. In all cases the complete corneal transplant was included in the lamellar flap. Laser ablation was performed in one case with the Schwind ${ }^{\circledR}$ Keratome I excimer system (Schwind, Kleinostheim, Germany) and in the other cases with the Wavelight $^{\circledR}$ Allegretto WaveEyeQ excimer laser (WaveLight AG, Erlangen, Germany). The treatment goal was primarily to reduce the refractive error to a great extent and not necessarily emmetropia since the preoperative refractive disorders were quite high (Table 1). Postoperatively, patients were treated with levofloxacin $\left(\right.$ Floxal $\left.^{\circledR}\right)$ and prednisolone (Inflanefran forte ${ }^{\circledR}$ ) eye drops four times a day for one week and unpreserved artificial tears for three months. All surgeries as well as the postoperative period were uneventful.
Statistical analysis was performed with SPSS $16.0^{\circledR}$ for Windows $^{\circledR}$ (SPSS Inc., Chicago, IL, USA). Statistically significant differences between data were determined by the Wilcoxon signed rank test. A $P$ value less than 0.05 was considered statistically significant.

\section{Results \\ Visual acuity}

Median preoperative UCVA (Figure 1) was 1 [logMar] (range 0.50 to 0.70 [logMar]), after lamellar keratotomy 1.15 [logMar] (range 0.50 to 0.70 [ $\log$ Mar]), and after laser ablation it improved to 0.4 [logMar] (range 0.70 to 0.20 [logMar]). Median gain of UCVA by the overall treatment was $7.38 \pm 2.96$ lines (range 2 to 12 lines) and was statistically highly significant $(P=0.008)$. Median change in UCVA by the keratotomy was $-0.5 \pm 1.41$ lines (range -4 to 0 lines) and was not statistically significant $(P=1)$. Median gain in lines of UCVA by the laser ablation was $7.88 \pm 3.03$ lines (range 2 to 12 lines) and statistically was highly significant $(P=0.008)$. Median preoperative BSCVA (Figure 2) was 0.2 [logMar] (range 1 to 0 [logMar]), after lamellar keratotomy 0.25 [logMar] (range 0.50 to 0 [logMar]), and after laser ablation 0.04 [logMar] (range 0.50 to 0 [logMar]). Median gain of BSCVA by the overall treatment was $1.63 \pm 3.07$ lines (range -1 to 8 lines) and not statistically significant $(P=0.25)$. Median change in BSCVA by the keratotomy was $0.75 \pm 1.83$ lines (range -1 to 5 lines) and not statistically significant $(P>0.4)$. Median gain in lines of BSCVA by the laser ablation was $0.87 \pm 1.64$ lines (range -1 to 3 lines) and statistically not significant $(P>0.2)$.

\section{Refraction}

Mean preoperative manifest refractive spherical equivalent (MRSE) (Figure 3) was $-4.02 \pm 4.77$ diopters (D) (range -11.00 to $+1.00 \mathrm{D})$, after lamellar keratotomy $-4.11 \pm 4.64 \mathrm{D}$

Table I Refraction before surgery, after lamellar keratotomy, intended refraction after laser ablation, and achieved refraction after laser ablation

\begin{tabular}{lllll}
\hline Case & Preoperative refraction & Refraction after keratotomy & Intended refraction & Refraction after laser ablation \\
\hline 1 & $+1.0-8.0 \times 55^{\circ}$ & $+0.50-7.25 \times 60^{\circ}$ & $-0.50-0.25 \times 60^{\circ}$ & $+2.0-1.0 \times 40^{\circ}$ \\
2 & $+6.50-11.0 \times 160^{\circ}$ & $+6.50-11.0 \times 165^{\circ}$ & $+6.50-6.0 \times 165^{\circ}$ & $+4.50-5.0 \times 155^{\circ}$ \\
3 & $+1.25-6.50 \times 7^{\circ}$ & $-0.50-4.50 \times 11^{\circ}$ & -0.50 & $0-0.75 \times 67^{\circ}$ \\
4 & $-6.25-6.0 \times 93^{\circ}$ & $-5.75-6.0 \times 89^{\circ}$ & $-3.75-3.0 \times 89^{\circ}$ & $-3.25-2.25 \times 85^{\circ}$ \\
5 & $-7.75-0.75 \times 28^{\circ}$ & $-8.75-0.25 \times 32^{\circ}$ & $-2.25-0.25 \times 32^{\circ}$ & $-1.75-0.50 \times 139^{\circ}$ \\
6 & $+2.50-6.50 \times 96^{\circ}$ & $+2.50-7.25 \times 96^{\circ}$ & $+0.50-1.0 \times 96^{\circ}$ & $-0.50-0.75 \times 175^{\circ}$ \\
7 & $-4.50-13.0 \times 144^{\circ}$ & $-4.50-12.0 \times 144^{\circ}$ & $0-1.0 \times 144^{\circ}$ & $-2.25-4.75 \times 155^{\circ}$ \\
8 & $+4.25-6.50 \times 105^{\circ}$ & $+4.0-5.50 \times 100^{\circ}$ & -0.25 & $+0.75-1.75 \times 122^{\circ}$ \\
\hline
\end{tabular}




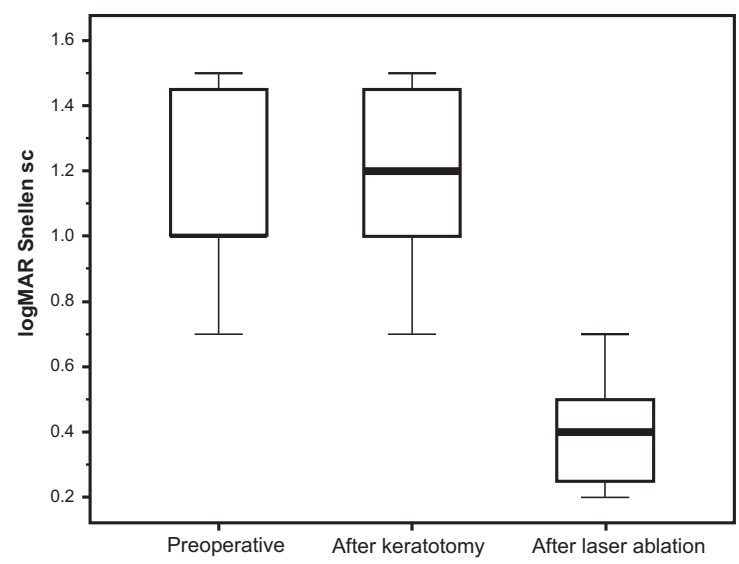

Figure I Median preoperative uncorrected visual acuity improved from preoperative I [logMar] to 0.4 [logMar] after laser ablation.

(range -10.50 to $+1.25 \mathrm{D}$ ), and after laser ablation $-1.11 \pm$ $2.45 \mathrm{D}$ (range -4.62 to $+2.00 \mathrm{D}$ ). Changes in MRSE by overall treatment and by keratotomy were not statistically significant. Change in MRSE by the laser ablation was statistically significant $(P=0.039)$. Mean preoperative sphere was $-0.38 \pm 5.16 \mathrm{D}$ (range -7.75 to $+6.50 \mathrm{D})$, after lamellar keratotomy $-0.75 \pm 5.22 \mathrm{D}$ (range -8.75 to $+6.50 \mathrm{D}$ ) and after laser ablation $-0.06 \pm 2.50 \mathrm{D}$ (range -3.25 to $+4.50 \mathrm{D})$. Change of the manifest sphere by the overall treatment and by each individual step was statistically not significant. Mean preoperative manifest astigmatism (Figure 4) was $-7.27 \pm 3.65 \mathrm{D}$ (range -13.0 to $-0.75 \mathrm{D}$ ), after lamellar keratotomy $-6.72 \pm 3.68 \mathrm{D}$ (range -12.0 to $-0.25 \mathrm{D}$ ), after laser ablation $-2.08 \pm 1.80 \mathrm{D}$ (range -5.0 to $-0.50 \mathrm{D}$ ). Change of the manifest astigmatism by the keratotomy alone was statistically not significant $(P=0.12)$. The change of manifest astigmatism by the overall treatment was statistically

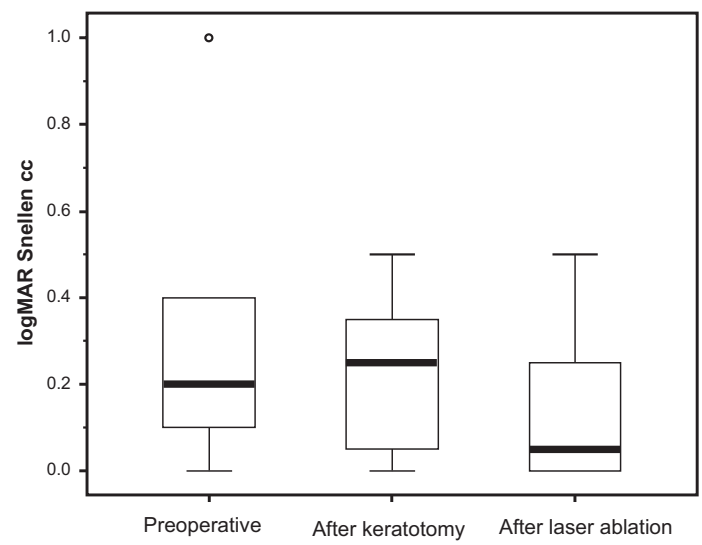

Figure 2 Median preoperative best spectacle-corrected visual acuity did not change significantly from 0.2 [logMar] preoperatively to 0.04 [logMar] after laser ablation.

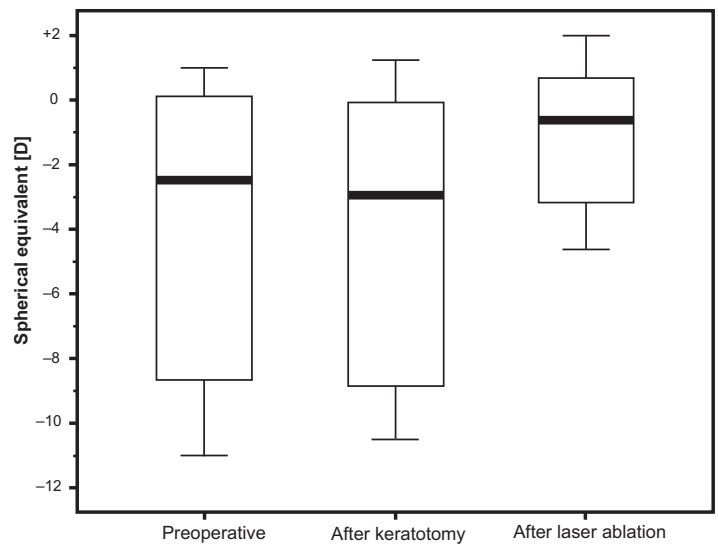

Figure 3 Mean preoperative manifest refractive spherical equivalent was reduced from preoperatively $-4.02 \mathrm{D} \pm 4.77$ to $-1.11 \mathrm{D} \pm 2.45$ after laser ablation.

highly significant $(P=0.008)$ as well as the change by the laser ablation alone $(P=0.016)$. Comparing the intended refraction with the achieved refraction after laser ablation there is a mean deviation of $1.16 \mathrm{D}$ (range -1.0 to $+4.0 \mathrm{D}$ ) in spherical equivalent (Table 1).

\section{Corneal topography}

Mean preoperative corneal refractive power was 44.24 $\pm 3.82 \mathrm{D}$ (range 37.50 to $49.85 \mathrm{D}$ ), after lamellar keratotomy $44.90 \pm 3.86 \mathrm{D}$ (range 39.14 to $51.10 \mathrm{D}$ ), and after laser ablation $42.38 \pm 3.24 \mathrm{D}$ (range 35.55 to $47.10 \mathrm{D}$ ). Changes of mean corneal refractive power by the overall treatment and by each individual step were not statistically significant $(P>0.05)$. Axis of the flattest meridian preoperatively was $72.75^{\circ} \pm 59.52$ (range $7.50^{\circ}$ to $159.60^{\circ}$ ), after lamellar keratotomy $95.10^{\circ} \pm 59.11$ (range $9.90^{\circ}$ to $162.80^{\circ}$ ), and after laser ablation $93.8^{\circ} \pm 64.91$

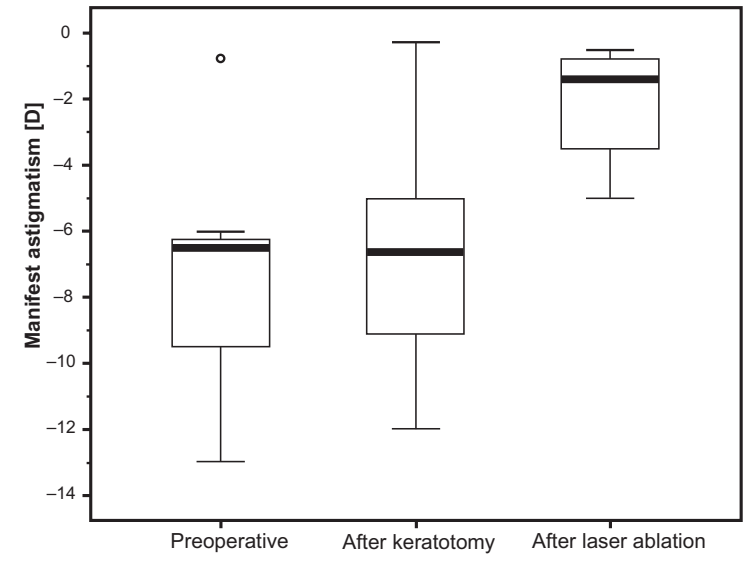

Figure 4 Manifest astigmatism was not affected significantly by the keratotomy. It was reduced from preoperatively $-7.27 \mathrm{D} \pm 3.65$ to $-2.08 \mathrm{D} \pm 1.80$ after laser ablation. 
(range $8.70^{\circ}$ to $175^{\circ}$ ). Axis of the steepest meridian preoperatively was $117.75^{\circ} \pm 45.14$ (range $60.20^{\circ}$ to $179.30^{\circ}$ ), after lamellar keratotomy $95.10^{\circ} \pm 56.37$ (range $22.10^{\circ}$ to $177.10^{\circ}$ ), and after laser ablation $93.8^{\circ} \pm 39.62$ (range $33.70^{\circ}$ to $139.3^{\circ}$ ). Changes of the axis of the flattest meridian by each individual step of the procedure and by the overall treatment were not statistically significant. Changes of the axis of the steepest meridian by the overall treatment were statistically significant $(P=0.039)$, changes by the keratotomy $(P>0.3)$ and by the laser ablation $(P>0.7)$ alone were statistically not significant.

\section{Corneal pachymetry}

Mean preoperative corneal pachymetry was $557.81 \pm 51.77 \mu \mathrm{m}$ (range 454.2 to $633.0 \mu \mathrm{m}$ ), after lamellar keratotomy $563.67 \pm 61.50 \mu \mathrm{m}$ (range 460.1 to $660.5 \mu \mathrm{m}$ ), and after laser ablation $473.06 \pm 60.39 \mu \mathrm{m}$ (range 383.5 to $574.9 \mu \mathrm{m}$ ).

\section{Discussion}

High refractive errors are a frequent finding after $\mathrm{PK}^{8-10}$ and reduce the patient's perception of success following corneal transplantation. High anisometropia impairs visual rehabilitation and compromises the patient's ability to return to normal binocular functions. Correcting these refractive disorders with spectacles is not possible in most of the cases when anisometropia exceeds $3 \mathrm{D}$. Contact lenses provide a high quality of vision, although they are associated with problems like intolerance, corneal vascularization, and risk of corneal infections. ${ }^{10-12}$ Some patients may face difficulties wearing contact lenses due to poor manual dexterity, tremor, or reduced visual acuity in the fellow eye. Surgical approaches such as relaxing incisions, ${ }^{13,14}$ wedge resection, ${ }^{15,16}$ and selective suture removal ${ }^{17}$ have been used to address these refractive errors, but provide less predictable and stable results and are associated with risk of wound dehiscence, induction of a graft rejection, and a long healing process with fluctuations of corneal topography and refraction. Lens surgery with the implantation of toric lenses ${ }^{18,19}$ or the implantation of additional intraocular lenses ${ }^{20}$ have shown good results, but it increases the risk of serious complications like endophthalmitis, elevation of intraocular pressure, retinal detachment, and loss of endothelial cells. Surface ablation such as photorefractive keratectomy ${ }^{21-24}$ and laser-assisted sub-epithelial keratomileusis ${ }^{25}$ have shown moderate results because of haze formation and regression of the refractive effect.

LASIK has been widely used since its inclusion in the clinical routine in the early 90 s to treat a great range of refractive disorders. By performing laser ablation in the corneal stroma, postoperative wound healing reaction is very mild and the risk of scarring and haze formation is very low. ${ }^{26,27}$ It combines a high patient convenience due to the lack of postoperative complaints and fast visual recovery with predictable, precise, and stable results. In addition the rate of serious complications is very low ${ }^{28,29}$ due to the evolution of the hardware used and the standardized procedure, which makes LASIK the most frequently used mode of treatment in corneal refractive surgery.

In our study, UCVA improved significantly after overall treatment. None of the patients lost a line of visual acuity and all improved by at least 2 and up to 12 lines on the Snellen chart. BSCVA did not change significantly; only one patient lost a line of BSCVA while the rest improved by up to 8 Snellen lines. These findings are accordant to other studies, ${ }^{2-7,30-36}$ which have shown LASIK as an effective mode of treatment for refractive errors following PK.

An open issue in performing LASIK after PK is whether the lamellar keratotomy alone causes alterations of the corneal shape and should therefore be performed in two steps, in order to obtain more predictable and precise results by collecting the necessary data for laser ablation after the corneal flap has stabilized and the refraction is stable. The analysis of the refraction showed no statistically significant changes in sphere and astigmatism by the lamellar keratotomy alone. Similarly, corneal refractive power showed no statistically significant changes concerning the amount of the refractive power, nor the axis of the steepest or flattest meridian. Comparing the preoperative refraction with the post-keratotomy refraction in detail, there was a decrease in myopic spherical equivalent of 0.25 to $1.5 \mathrm{D}$ in half of the patients, whereas an increase was seen only in one patient (Table 1). Comparing the preoperative cylinder with the post-keratotomy cylinder (Table 1) there was a reduction of the preoperative cylinder in five out of eight patients of $0.5 \mathrm{D}$ up to 2.0 D. These changes were statistically not significant, probably due to the small size of our patient cohort. However, these changes would definitely have an impact when planning a refractive surgery. Our results match only in part those of the studies conducted by Lee and colleagues ${ }^{37}$ and Bussin and colleagues ${ }^{38}$ who found a significant reduction of preoperative sphere and cylinder after keratotomy.

The goal of our treatment was not the same as for correcting refractive disorders in other refractive patients due to the height of the preoperative refraction with the exception of patient number 5 (Table 1). It was primarily the reduction of refractive errors to an extent that correction of the residual 
refractive error by other means like spectacle or contact lenses is possible. In addition, assessing data from refraction means and corneal topography is often difficult. Based on preoperative data of limited certainty, it is not necessarily desirable to try to reach the maximal feasible ablation depth in order to reach emmetropia, which endangers the outcome of the entire procedure. The precision of laser ablation was satisfactory when preoperative data showing high refractive errors was considered. Regarding the spherical equivalent, three patients were overcorrected, four patients were undercorrected, and one patient was on target. All surgeries were uneventful. We did not face any complications while creating the corneal flap or relifting it before laser ablation. Wound healing reaction was mild and no incidence of graft rejection occurred during the period of review.

Many factors such as the size, curvature, and thickness of the corneal transplant, the underlying disease for the PK, preoperative refraction, the trephination technique, the type of suture, size and alignment of the corneal flap, whether the complete transplant is included in the lamellar flap or not, location of the hinge, the kind of mikrokeratome, and the used settings (advance rate, vacuum), the excimer laser and the chosen ablation profile as well as healing processes which vary among patients affect the refractive outcome of LASIK after PK. The interactions between these factors are to a great extent still unknown. Keratotomy causes biomechanical changes in the cornea after PK and these are unpredictable. Despite the small patient sample of this study and its limited validity we share the opinion of Alio and colleagues $^{30}$ and Kwitko and colleagues ${ }^{33}$ and favor a two-step approach. Further clinical studies are necessary to investigate the biomechanical effects of keratotomy in corneal grafts in order to clarify whether a one-step or two-step LASIK is the most eligible method to improve precision and predictability of LASIK after corneal transplantation.

\section{Disclosures}

The authors report no conflicts of interest in this work.

\section{References}

1. Perlman EM. An analysis and interpretation of refractive errors after penetrating keratoplasty. Ophthalmology. 1981;88:39-45.

2. Afshari NA, Schirra F, Rapoza PA, et al. Laser in situ keratomileusis outcomes following radial keratotomy, astigmatic keratotomy, photorefractive keratectomy, and penetrating keratoplasty. J Cataract Refract Surg. 2005;31:2093-2100.

3. Arenas E, Maglione A. Laser in situ keratomileusis for astigmatism and myopia after penetrating keratoplasty. J Refract Surg. 1997;13:27-32.

4. Buzard K, Febbraro JL, Fundingsland BR. Laser in situ keratomileusis for the correction of residual ametropia after penetrating keratoplasty. J Cataract Refract Surg. 2004;30:1006-1013.
5. Forseto AS, Francesconi CM, Nose RA, et al. Laser in situ keratomileusis to correct refractive errors after keratoplasty. J Cataract Refract Surg. 1999;25:479-485.

6. Hardten DR, Chittcharus A, Lindstrom RL. Long term analysis of LASIK for the correction of refractive errors after penetrating keratoplasty. Cornea. 2004;23:479-489.

7. Nassaralla BR, Nassaralla JJ. Laser in situ keratomileusis after penetrating keratoplasty. J Refract Surg. 2000;16:431-437.

8. Assil KK, Zarnegar SR, Schanzlin DJ. Visual outcome after penetrating keratoplasty with double continuous or combined interrupted and continuous suture wound closure. Am J Ophthalmol. 1992;114:63-71.

9. Binder PS. The effect of suture removal on postkeratoplasty astigmatism. Am J Ophthalmol. 1988;106:507.

10. Perl T, Charlton KH, Binder PS. Disparate diameter grafting. Astigmatism, intraocular pressure, and visual acuity. Ophthalmology. 1981;88:774-781.

11. Genvert GI, Cohen EJ, Arentsen JJ, et al. Fitting gas-permeable contact lenses after penetrating keratoplasty. Am J Ophthalmol. 1985;99:511-514.

12. MacRae SM, Matsuda M, Yee R. The effect of long-term hard contact lens wear on the corneal endothelium. CLAO J. 1985;11:322-326.

13. Arffa RC. Results of a graded relaxing incision technique for post keratoplasty astigmatism. Ophthalmic Surg. 1988;19:624-628.

14. Hardten DR, Lindstrom RL. Surgical correction of refractive errors after penetrating keratoplasty. Int Ophthalmol Clin. 1997;37:1-35.

15. Lugo M, Donnenfeld ED, Arentsen JJ. Corneal wedge resection for high astigmatism following penetrating keratoplasty. Ophthalmic Surg. 1987;18:650-653.

16. Troutman RC. Corneal wedge resections and relaxing incisions for postkeratoplasty astigmatism. Int Ophthalmol Clin. 1983;23:161-168.

17. Goren MB, Dana MR, Rapuano CJ, et al. Corneal topography after selective suture removal for astigmatism following keratoplasty. Ophthalmic Surg Lasers. 1997;28:208-214.

18. Amm M, Halberstadt M. Implantation of toric intraocular lenses for correction of high post-keratoplasty astigmatism. Ophthalmologe. 2002;99:464-469.

19. Mohammadpour M. Toric IOL and postkeratoplasty astigmatism. Ophthalmology. 2007;114:825-826.

20. Tahzib NG, Cheng YY, Nuijts RM. Three-year follow-up analysis of Artisan toric lens implantation for correction of postkeratoplasty ametropia in phakic and pseudophakic eyes. Ophthalmology. 2006;113:976-984.

21. Amm M, Duncker GI, Schroder E. Excimer laser correction of high astigmatism after keratoplasty. J Cataract Refract Surg. 1996;22:313-317.

22. Bilgihan K, Ozdek SC, Akata F, et al. Photorefractive keratectomy for post-penetrating keratoplasty myopia and astigmatism. J Cataract Refract Surg. 2000;26:1590-1595.

23. Chan WK, Hunt KE, Glasgow BJ, et al. Corneal scarring after photorefractive keratectomy in a penetrating keratoplasty. Am J Ophthalmol. 1996;121:570-571.

24. Georgaras SP, Neos G, Margetis SP, et al. Correction of myopic anisometropia with photorefractive keratectomy in 15 eyes. Refract Corneal Surg. 1993;9:S29-S34.

25. Rajan MS, O’Brart DP, Patel P, et al. Topography-guided customized laser-assisted subepithelial keratectomy for the treatment of postkeratoplasty astigmatism. J Cataract Refract Surg. 2006;32:949-957.

26. Pallikaris IG, Papatzanaki ME, Stathi EZ, et al. Laser in situ keratomileusis. Lasers Surg Med. 1990;10:463-468.

27. Pallikaris IG, Siganos DS. Excimer laser in situ keratomileusis and photorefractive keratectomy for correction of high myopia. $J$ Refract Corneal Surg. 1994;10:498-510.

28. Arevalo JF. Posterior segment complications after laser-assisted in situ keratomileusis. Curr Opin Ophthalmol. 2008;19:177-184.

29. Knorz MC. Flap and interface complications in LASIK. Curr Opin Ophthalmol. 2002;13:242-245. 
30. Alió JL, Javaloy J, Osman AA, et al. Laser in situ keratomileusis to correct post-keratoplasty astigmatism; 1-step versus 2-step procedure. J Cataract Refract Surg. 2004;30:2303-2310.

31. Colin J, Abdelkefi A. Two-step laser in situ keratomileusis to correct high astigmatism after corneal autograft. J Cataract Refract Surg. 2006;32:1966-1967.

32. Donnenfeld ED, Kornstein HS, Amin A, et al. Laser in situ keratomileusis for correction of myopia and astigmatism after penetrating keratoplasty. Ophthalmology. 1999;106:1966-1974.

33. Kwitko S, Marinho DR, Rymer S, et al. Laser in situ keratomileusis after penetrating keratoplasty. J Cataract Refract Surg. 2001;27:374-379.

34. Mann E, Zaidman GW, Shukla S. Efficacy of nonsimultaneous bilateral LASIK after nonsimultaneous bilateral penetrating keratoplasty. Cornea. 2006;25:1053-1056.
35. Mularoni A, Laffi GL, Bassein L, et al. Two-step LASIK with topography-guided ablation to correct astigmatism after penetrating keratoplasty. J Refract Surg. 2006;22:67-74.

36. Preschel N, Hardten DR, Lindstrom RL. LASIK after penetrating keratoplasty. Int Ophthalmol Clin. 2000;40:111-123.

37. Lee GA, Perez-Santonja JJ, Maloof A, et al. Effects of lamellar keratotomy on postkeratoplasty astigmatism. $\mathrm{Br} J$ Ophthalmol. 2003;87:432-435.

38. Busin M, Arffa RC, Zambianchi L, et al. Effect of hinged lamellar keratotomy on postkeratoplasty eyes. Ophthalmology. 2001;108: 1845-1851.
Clinical Ophthalmology

\section{Publish your work in this journal}

Clinical Ophthalmology is an international, peer-reviewed journal covering all subspecialties within ophthalmology. Key topics include: Optometry; Visual science; Pharmacology and drug therapy in eye diseases; Basic Sciences; Primary and Secondary eye care; Patient Safety and Quality of Care Improvements. This journal is indexed on

\section{Dovepress}

PubMed Central and CAS, and is the official journal of The Society of Clinical Ophthalmology (SCO). The manuscript management system is completely online and includes a very quick and fair peer-review system, which is all easy to use. Visit http://www.dovepress.com/ testimonials.php to read real quotes from published authors. 